\title{
EFEITO DO CICLO TÉRMICO NAS TRANFORMAÇÕES DE FASE DE UM AÇO CARBONO COM MICRO ADIÇÃO DE NIÓBIO E MOLIBDÊNIO*
}

\author{
Mônica Aline Magalhães Gurgel ${ }^{1}$ \\ Andersan dos Santos Paula ${ }^{2}$ \\ Fernando Generoso Neiva Ferreira ${ }^{3}$ \\ Saulo Brinco Diniz ${ }^{4}$
}

\section{Resumo}

Este trabalho avaliou a evolução estrutural e mecânica dos ciclos térmicos realizados em uma chapa laminada a frio de aço baixo carbono com micro adição de molibdênio e nióbio destinado para a indústria automobilística, associado a classe dos aços bifásicos. Para realização do estudo foi feita a caracterização microestrutural e mecânica, por intermédio de amostras retiradas após a laminadas a frio produzidas em escala industrial, com auxílio das técnicas de microscopia óptica, e avaliação da dureza via Nanoindentador Instrumentado. Os ciclos térmicos foram feitos com o intuito de observar os processos de recuperação, recristalização, e transformação de fases no aquecimento e após resfriamento, com encharque em distintas temperaturas do campo intercrítico, via análise de dilatometria em um equipamento de análise termomecânica (TMA) em amostras extraídas da chapa laminada a frio "Full- Hard".

Palavras-chave: Aço bifásico; Ciclo térmico; Microestrutura; Laminação a frio.

\section{THERMAL CYCLE EFFECT ON THE MOLIBDENIM AND NIOBIUM MICRO- ADDTION LOW CARBON STEEL PHASE TRANSFORMATIONS}

\section{Abstract}

This study evaluated the structural and mechanical evolution of the thermal cycles carried out in a low carbon steel with molybdenum and niobium micro-addition coldrolled sheet destined for the automotive industry, associated to dual-phase steels grade. For realization of the study was performed the microstructural and mechanical characterization, through full-hard cold-rolled samples produced in industrial scale, by optical microscopy and instrumented nanoindentation techniques. The thermal cycles were carried out in order to observe the recovery and recrystallization progress, and phase transformation on heating and after cooling, with distinct soaking temperatures in the intercritic field, by dilatometric analysis in a thermo-mechanical analyser (TMA) using a full-hard cold-rolled samples.

Keywords: Dual-phase steel; Thermal cycle; Microstructure; Cold rolling.

1 Engenheira Metalurgista, Mestranda da PPGEM, UFF, Volta Redonda, RJ, Brasil

2 Engenheira Metalurgista, D.Sc., Professor Adjunta, Instituto Militar de Engenharia, Rio de Janeiro, $R J$, Brasil; e orientadora credenciada da PPGEM, UFF, Volta Redonda, RJ, Brasil.

3 Engenheiro Desenvolvimento, M.Sc., Eng. Desen. Sênior, Companhia Siderúrgica Nacional, Volta Redonda, RJ, Brasil.

4 Engenheiro Metalurgista, M.Sc., Doutorando em Ciências dos Materiais, Instituto Militar de Engenharia, Rio de Janeiro, RJ. 


\section{INTRODUÇÃO}

Com a crescente preocupação ambiental nas últimas décadas, as indústrias automobilísticas começaram a buscar estruturas/peças mais leves, para que reduzissem assim o consumo de combustível e consequentemente a eliminação de poluentes, não esquecendo a segurança dos passageiros, fez com que as indústrias siderúrgicas buscassem inovações nos materiais produzidos, desenvolvendo assim aços de maior valor tecnológico, que proporcionam uma redução da sua espessura sem perda nas suas propriedades mecânicas. Exigência esta que resultou no desenvolvimento nos últimos anos de várias classes de materiais, capazes de substituir os aços ao carbono, dentre elas a classe dos aços avançados de alta resistência ("Advanced High-Strength Steels" (AHSS)) onde encontramos os aços bifásicos ou "Dual Phase" (DP) que será alvo de estudo desse trabalho, que são utilizados em boa parte de um automóvel, principalmente, nas partes que exigem uma maior tenacidade.

O aço bifásico ("Dual Phase" ou DP), surgiu industrialmente ao final da década de 70, porém por questão de limitação de processo e equipamentos siderúrgicos teve dificuldades iniciais de ser difundido industrialmente, principalmente no que diz respeito ao cenário siderúrgico brasileiro. Este aço possui uma microestrutura constituída de uma matriz ferrítica macia com ilhas de martensita dura, dependendo dos parâmetros do processamento podemos encontrar nesses materiais constituintes como a perlila e bainita, essa microestrutura mais complexa, que as dos aços ao carbono, é a responsável por maximizar a ductilidade e a resistência mecânica dos aços [1]. Os aços bifásicos combinam uma considerável resistência mecânica, conformabilidade e boa soldabilidade.

Devido as propriedades e a crescente utilização desse material, torna-se necessário ampliar as pesquisas no cenário brasileiro sobre os aços bifásicos e dessa maneira é fundamental conhecer melhor seu processo de fabricação buscando a definição de uma composição química específica e o entendimento da evolução de suas características estruturais ao longo de todas as etapas de produção [2-4].

Neste trabalho, analisou-se amostras de um aço baixo carbono com microadição de $\mathrm{Nb}$ e Mo retiradas após a laminação a frio, em escala industrial, com composição química específica, para avaliação da evolução microestrutural via microscopia óptica e da propriedade mecânica dureza com auxílio de um nanoindentador instrumentado. A partir da análise crítica em função da taxa de aquecimento quanto a ocorrência dos fenômenos de recuperação, recristalização e transformação de fases no aquecimento e após resfriamento, com encharque no intervalo do campo intercrítico, via análise de dilatometria em um equipamento de análise termomecânica (TMA), em amostras extraídas da chapa laminada a frio "Full-Hard".

\section{MATERIAIS E MÉTODOS}

\subsection{Material}

O material em estudo é um aço baixo carbono com microadição de Nióbio e Molibdênio retiradas após a etapa de laminação a frio (LF) da produção em escala industrial da Usina Presidente Vargas (UPV) - Companhia Nacional Siderúrgica (CSN) - Volta Redonda / Rio de Janeiro. Na tabela 1 é apresentada a composição química do material pelas faixas de percentual em peso, devido sigilo industrial. 
Tabela 1. Especificação da composição química do material em estudo

\begin{tabular}{|c|c|c|c|c|c|c|c|}
\hline \multicolumn{7}{|c|}{ Composição Química (\% em peso) } \\
\hline $\mathbf{C}$ & $\mathbf{M n}$ & $\mathbf{M o}$ & $\mathbf{N i}$ & $\mathbf{C r}$ & $\mathbf{A L}$ & $\mathbf{N b}$ & $\mathbf{S i}$ \\
\hline $0,11-$ & $1,60-$ & $0,10-$ & 0,10 & 0,10 & 0,010 & 0,030 & 0,05 \\
0,15 & 1,80 & 0,30 & máx & máx & mín & máx & máx \\
\hline
\end{tabular}

As chapas laminadas a frio usadas nesse trabalho foram resultado de uma redução de $60 \%$ das chapas laminadas a quente resultantes do processo de laminação a quente de acordo com o fluxo da CSN e passaram a ter uma espessura de aproximadamente $1,20 \mathrm{~mm}$.

\subsection{Métodos}

\subsubsection{Análise termomecânica}

Para observar e verificar as temperaturas associadas aos processos de restauração da estrutura deformada, por meio de recuperação e recristalização da mesma, e transformação de fase $\alpha \rightarrow \gamma$, foram realizados ensaios de dilatometria em um equipamento de análise termomecânica (TMA) da marca Shimadzu, modelo TMA-60. Bem como observar pelas evidencias na curva dilatométrica as transformações de fase que poderiam se fazer presentes durante o aquecimento até a temperatura de encharque no intervalo do campo intercrítico. Além da análise indireta por microscopia óptica e nanoindentação dos produtos de transformação resultantes dos distintos ciclos térmicos. Os corpos de prova para estas análises tiveram dimensões aproximadas de $5 \times 5 \times 1,2 \mathrm{~mm}$, e foram imersos em uma solução de $50 \%$ de ácido nítrico (HNO3) e 50\% de ácido Fluorídrico (HF) durante aproximadamente 1 minutos, de modo a remover a camada encruada formada pelo corte de precisão em disco diamantado. Para tal ensaio, aqueceu-se corpos de provas do aço na condição laminada a frio "Full Hard", em duas maneiras: (i) cinco amostras distintas, da temperatura ambiente até as temperaturas de $680^{\circ} \mathrm{C}, 740^{\circ} \mathrm{C}, 800^{\circ} \mathrm{C}, 860^{\circ} \mathrm{C}$ e $920^{\circ} \mathrm{C}$ com a mesma taxa de aquecimento de $99^{\circ} \mathrm{C} / \mathrm{min}$, com um encharque de 3 minutos e posterior resfriamento com uma taxa de $10^{\circ} \mathrm{C} / \mathrm{min}$; e (ii) uma amostra da temperatura, da temperatura ambiente até a temperatura de $920^{\circ} \mathrm{C}$ com uma taxa de aquecimento e resfriamento igual a $10^{\circ} \mathrm{C} / \mathrm{min}$, com o mesmo tempo de encharque (3 minutos) e taxa de resfriamento $\left(10^{\circ} \mathrm{C} / \mathrm{min}\right)$ empregue nas amostras anteriormente citadas. O uso de duas taxas de aquecimento para a temperatura de encharque de $920^{\circ} \mathrm{C}$ foi devido a buscar evidencias para comprovar que toda a modificação estrutural em estudo (recristalização e transformação de fase) deu-se somente na etapa de encharque nos tratamentos térmicos realizadas, ou seja, inibição destes fenômenos durante a etapa de aquecimento em função da elevada taxa de aquecimento - caracterizando assim a configuração do recozimento contínuo. Na tabela 2 é apresentada a identificação de cada amostra de acordo com o ciclo térmico aplicado.

Tabela 2. Identificação das amostras do Gráfico de microdureza

\begin{tabular}{|c|c|c|c|c|c|c|}
\hline Identificação & AM 1 & AM 2 & AM 3 & AM 4 & AM 5 & AM 6 \\
\hline Taxa de Aquecimento $\left({ }^{\circ} \mathrm{C} / \mathrm{min}\right)$ & 10 & \multicolumn{5}{|c|}{10} \\
\hline Taxa de resfriamento $\left({ }^{\circ} \mathrm{C} / \mathrm{min}\right)$ & \multicolumn{7}{|c|}{90} \\
\hline Temperatura máxima $\left({ }^{\circ} \mathrm{C}\right)$ & 920 & 680 & 740 & 800 & 860 & 920 \\
\hline
\end{tabular}




\subsubsection{Caracterização microestrutural e mecânica}

Para a preparação metalográfica, após corte com disco abrasivo e embutimento a quente, foi realizado o processo de lixamento com lixas de carbeto de silício $(220,320,400,600$, 800,1000 e 1200 mesh), fazendo uso de água como líquido refrigerante. O polimento foi manual e realizado em uma politriz com pano de feltro e pasta de diamante nas granulometrias de 6, 3 e $1 \mu \mathrm{m}$, com lubrificante Azul da Arotec para Ferrosos. Para análise da morfologia das microestruturas obtidas com o ciclo térmico, as amostras foram atacadas com Nital 3\% (3\% de ácido nítrico e $97 \%$ de álcool etílico PA), por esfregamento por 10 segundos, ou até que as amostras ficassem foscas. As amostras foram observadas utilizando-se um Microscópio Óptico (MO), equipamento Olympus GX71 acoplado a uma câmera digital e controlado pelo software "Image Pro Plus", instalado na Escola de Engenharia Industrial Metalúrgica de Volta Redonda (EEIMVR) da Universidade Federal Fluminense (UFF).

\subsubsection{Ensaio de nanoindentação instrumentada}

O ensaio de nanoindentação instrumentada foi realizado para obter informações quanto as possíveis mudança nas características mecânicas das amostras em estudo em função das mudanças microestruturais devido aos ciclos térmicos adotados. Os ensaios foram executados no Laboratório de Caracterização de Materiais Multiusuários no Instituto de Ciências Exatas (ICEX) da Universidade Federal Fluminense (UFF), em Volta Redonda em um nanoindentador da Shimadzu, Modelo DUH - 211S, com indentador do tipo Vickers. As medidas foram feitas utilizando carga de $100 \mathrm{gf}$, com ciclo de carga e descarga e 20 s de permanência nas cargas máxima e mínima, com 10 medidas por amostras das condições em estudo, de modo a estimar os valores médio de dureza (HV), das durezas dinâmicas (DHV-1 - elasto-plástica, e DHV-2 plástica), do módulo da indentação, e seus respectivos desvios padrão.

\section{RESULTADOS E DISCUSSÃO}

Com o intuito de observar a forma como se deram os processos de recuperação, recristalização e transformação de fase durante o aquecimento, foram realizadas análises de dilatometria do material laminado a frio "Full Hard" submetido a ciclos térmicos com taxa de 10 e $90^{\circ} \mathrm{C} / \mathrm{min}$ até a temperatura de encharque de $920^{\circ} \mathrm{C}$, conforme as curvas apresentadas na Figura 1. Onde observa-se que com aumento da taxa de aquecimento há um deslocamento dos fenômenos de recuperação e recristalização, bem como as transformações de fases para temperatura mais altas. Fazendo-se com que na taxa mais elevada $\left(99^{\circ} \mathrm{C} / \mathrm{min}\right)$ que as transformações de fases se complete durante o encharque. Estes resultados permitem assim dizer que nas condições de recozimento contínuo em escala industrial, onde se aplicam taxas de aquecimento maiores, que a recristalização e a transformação de fase pela formação de austenita irá se dar por completo ao longo do patamar na temperatura de encharque. 


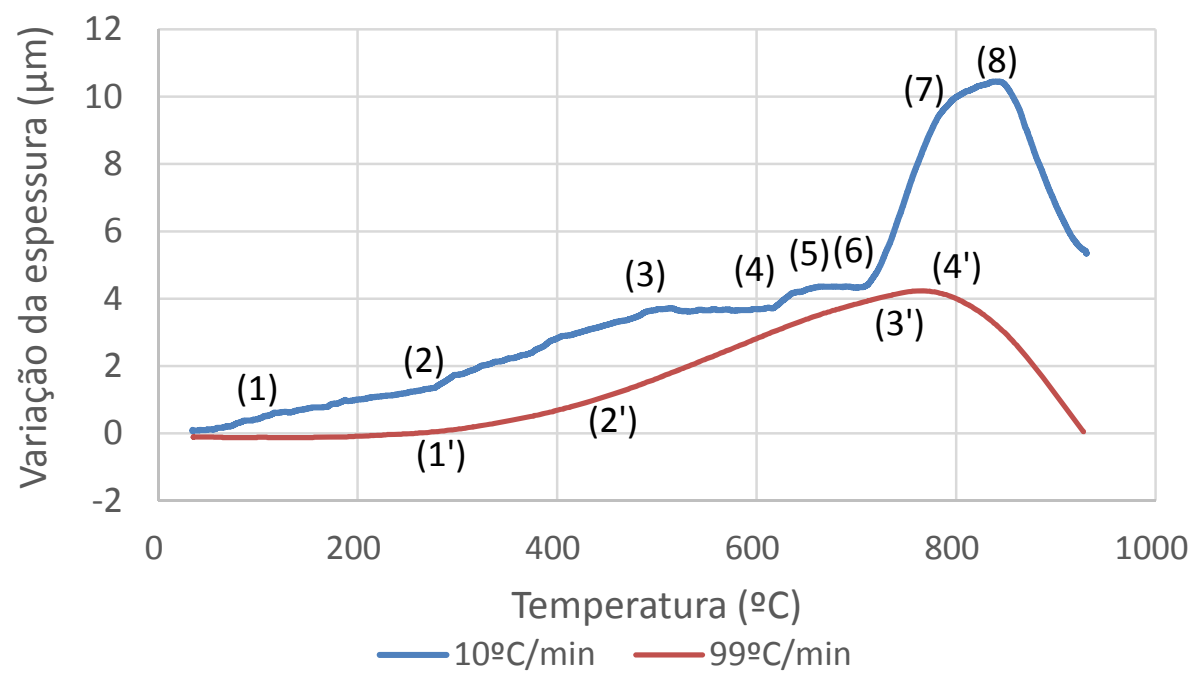

Figura 1. Análise de dilatometria do material na condição laminada a frio "Full Hard" submetido a taxas de aquecimento de $10^{\circ} \mathrm{C} / \mathrm{min}$ (curva superior - amostra 1) e $99^{\circ} \mathrm{C} / \mathrm{min}$ (curva inferior - amostra 6). Pontos: (1) e (1') início do processo de recuperação; (2) e (2') termino processo de recuperação e início do processo de recristalização; (3) término do processo de recristalização; (3') competição entre a recristalização e início de transformação de fases; (4) a (8) transformações de fases (decomposição $\mathrm{Fe}_{3} \mathrm{C}$ e $\alpha \rightarrow \gamma$ ); (3') e (4') decomposição $\mathrm{Fe}_{3} \mathrm{C}$ e início $\alpha \rightarrow \gamma$.

De posse das amostras, após a realização dos ciclos térmicos no TMA, procedeu as análises microestrutural, conforme as micrografias apresentadas nas Figuras 2 e 3. Quando se compara as amostras submetidas a temperatura de encharque de $920^{\circ} \mathrm{C}$, porém sujeitas a taxas de aquecimentos distintas, $10^{\circ} \mathrm{C} / \mathrm{min}$ (Figura 2) e $99^{\circ} \mathrm{C} / \mathrm{min}$ (Figura $3 \mathrm{e}$ ), com taxas de resfriamento iguais $\left(10^{\circ} \mathrm{C} / \mathrm{min}\right)$, verifica-se a presença de uma matriz ferrítica com alguns grãos perlíticos, porém uma distribuição mais homogênea da perlita para amostra submetida a taxa de aquecimento mais lenta (Figura 2).

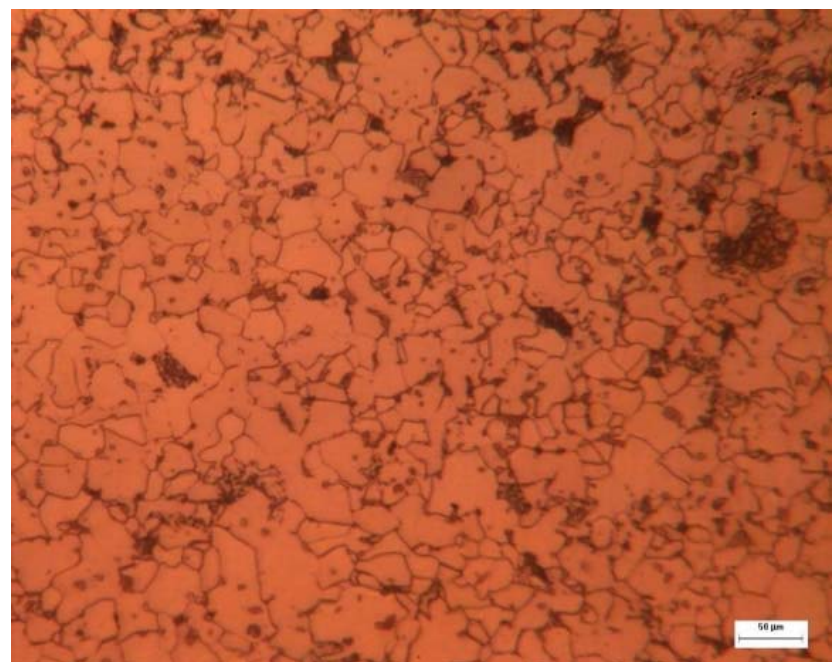

Figura 2. Caracterização microestrutural da amostra 1 após análise termomecânica com taxa de $10^{\circ} \mathrm{C} /$ min no aquecimento e resfriamento e temperatura de encharque de $920^{\circ} \mathrm{C}$, aumento de $500 \mathrm{x}$. 

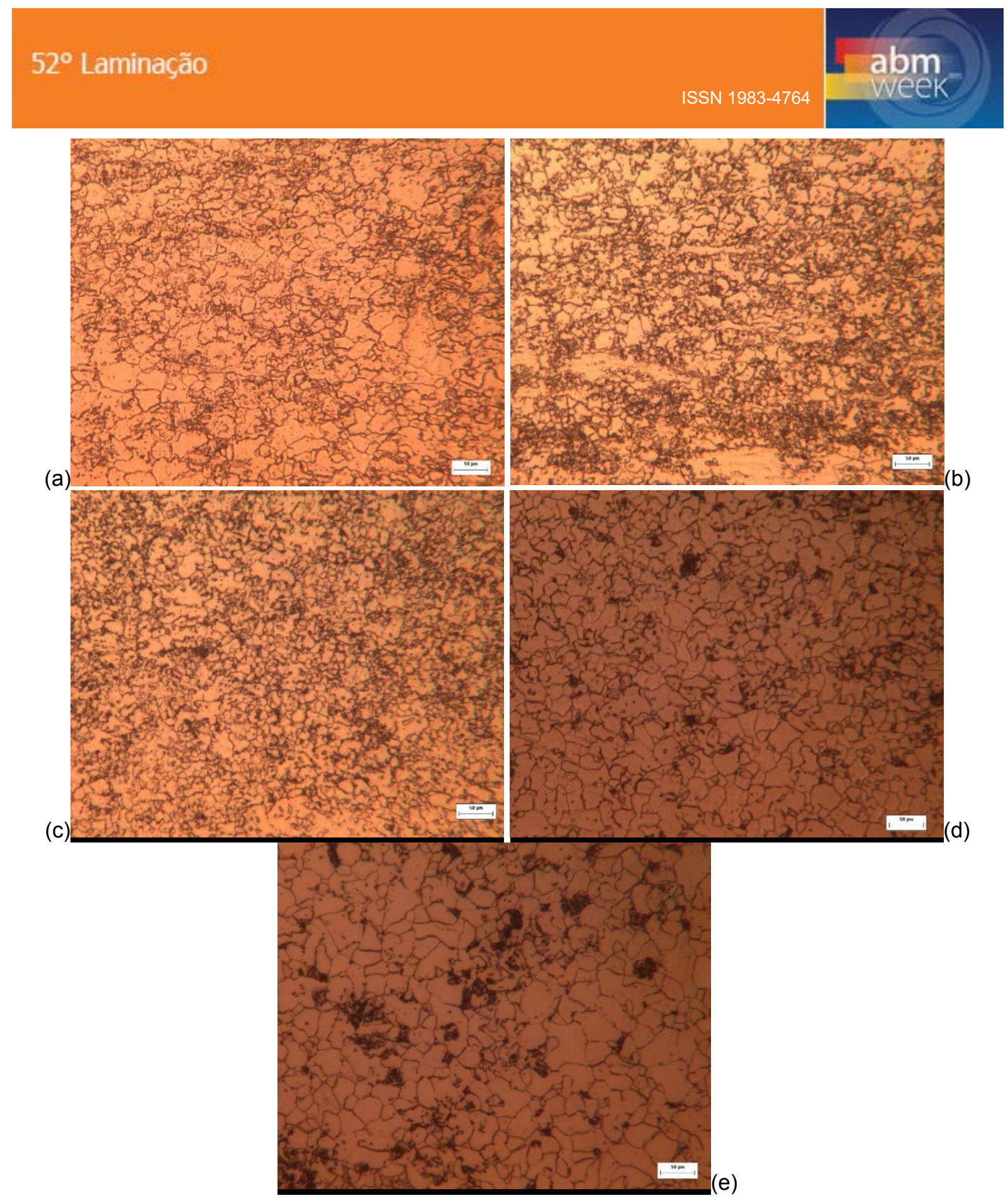

Figura 3. Caracterização microestrutural das amostras após análise termomecânica com taxa de aquecimento de $99^{\circ} \mathrm{C} / \mathrm{min}$ e taxa de resfriamento de $10^{\circ} \mathrm{C} / \mathrm{min}$ levando à temperatura máxima de: (a) $680^{\circ} \mathrm{C}$, (b) $740^{\circ} \mathrm{C}$, (c) $800^{\circ} \mathrm{C}$, (d) $860^{\circ} \mathrm{C}$, (e) $920^{\circ} \mathrm{C}$, todas com aumento de $500 \mathrm{x}$.

Por outro lado, ao se comparar as amostras submetidas as mesmas condições de taxas de aquecimento $\left(99^{\circ} \mathrm{C} / \mathrm{min}\right)$ e resfriamento $\left(10^{\circ} \mathrm{C} / \mathrm{min}\right)$, porém com temperaturas de encharque distintas (Figura 3), observa-se que uma microestrutura mais refinada para as temperaturas de encharque de $680^{\circ} \mathrm{C}$ (Figura 3a), $740^{\circ} \mathrm{C}$ (Figura $3 \mathrm{~b}$ ) e $800^{\circ} \mathrm{C}$ (Figura 3c), onde não se é possível precisar a natureza da segunda fase em conjunto com a matriz ferrítica pela análise no microscópio óptico. No entanto para as temperaturas de encharque de $860^{\circ} \mathrm{C}$ (Figura 3d) e $920^{\circ} \mathrm{C}$ (Figura 3e) a microestrutura torna-se mais grosseira com o incremento da temperatura, sendo a segunda fase associada a perlita - principalmente para a condição de encharque a $920^{\circ} \mathrm{C}$.

Com auxílio do nanoindentador instrumentado foram avaliadas as características mecânicas das amostras em estudo nesse trabalho, com carga de $100 \mathrm{gf}$ em posições distintas no plano das chapas, após a devida preparação metalográfica. Os valores 
médios e seus respectivos desvios padrão de algumas das propriedades obtidas com os ensaios de nanoindentação foram relacionados graficamente como mostrado na Figuras de 4 a 7.

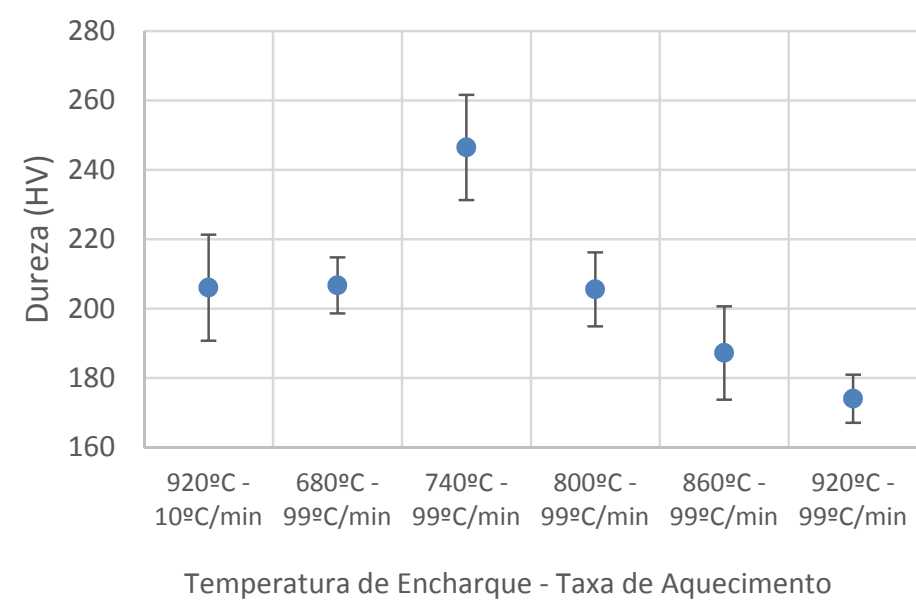

Figura 4. Valores da Dureza Vickers (HV), média e desvio padrão, para as amostras em estudo, com base nas taxas de aquecimento e temperaturas de encharque adotadas.

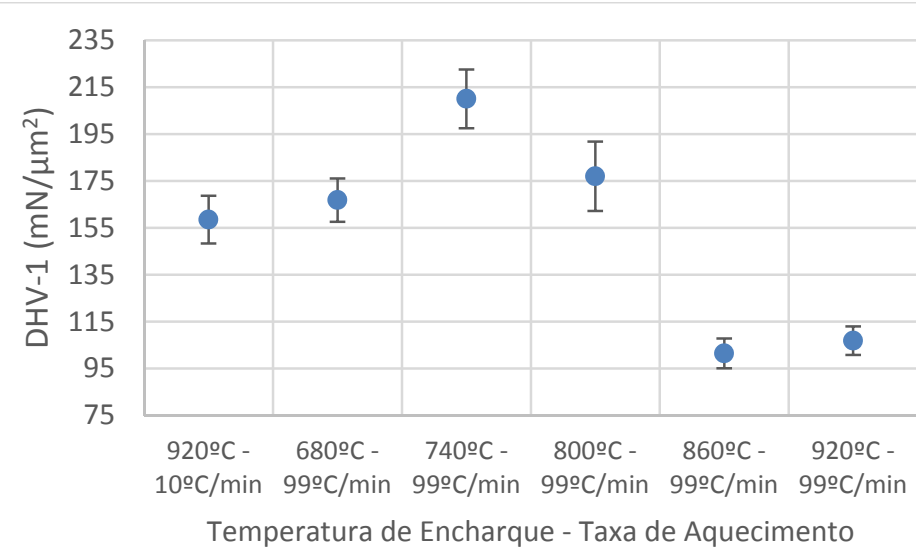

Figura 5. Valores da Dureza Dinâmica Elasto-plástica (DHV-1), média e desvio padrão, para as amostras em estudo, com base nas taxas de aquecimento e temperaturas de encharque adotadas.

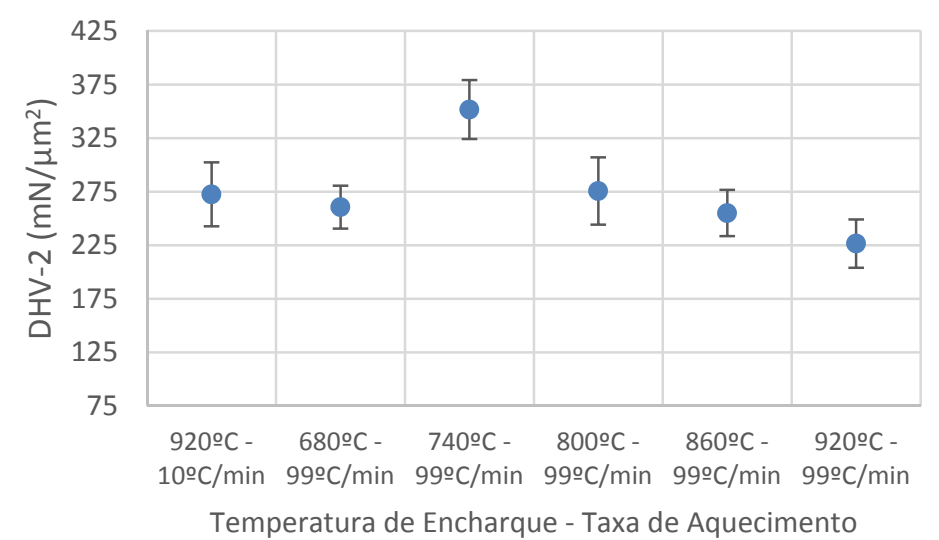

Figura 6. Valores da Dureza Dinâmica Plástica (DHV-2), média e desvio padrão, para as amostras em estudo, com base nas taxas de aquecimento e temperaturas de encharque adotadas. 


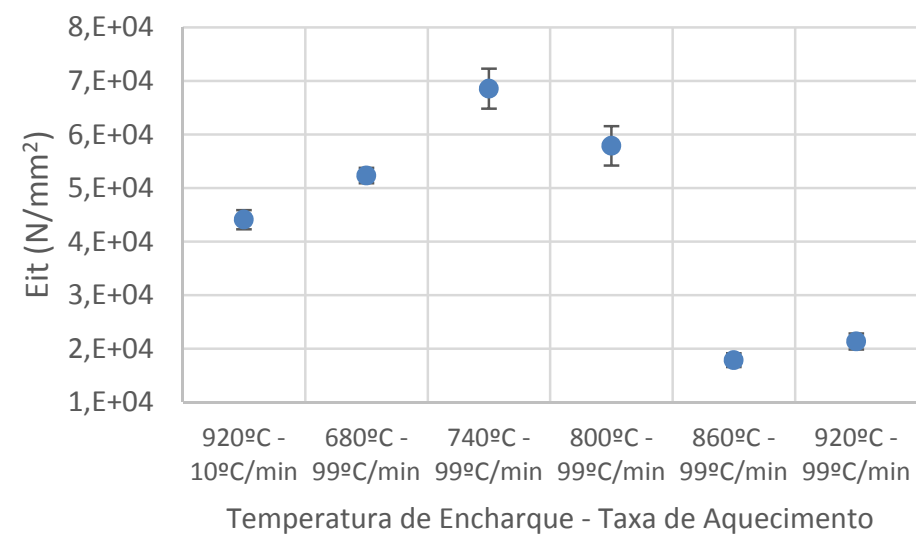

Figura 7. Valores do Módulo da Indentação (Eit), média e desvio padrão, para as amostras em estudo, com base nas taxas de aquecimento e temperaturas de encharque adotadas.

Do ensaio de nanoindentação além das informações de dureza Vickers (HV), Figura 4, foram extraídas informações relativas as durezas medidas no modo dinâmico levando em consideração a deformação total (elasto-plástica - DHV-1, Figura 5) e somente a componente de deformação plástica (DHV-2, Figura 6), além dos valores do módulo da indentação (Eit, Figura 7) que se correlação com o módulo de elasticidade do material.

Comparando-se as amostras que foram submetidas a uma mesma temperatura de encharque $\left(920^{\circ} \mathrm{C}\right)$ e taxas de aquecimento distintas $\left(10^{\circ} \mathrm{C} / \mathrm{min}\right.$ e $\left.99^{\circ} \mathrm{C} / \mathrm{min}\right)$, pode-se observar para as todas as propriedades avaliadas (Figuras de 4 a 7 ) valores de média e desvio padrão superiores para a condição com taxa de aquecimento de $10^{\circ} \mathrm{C} / \mathrm{min}$. Comportamento este que vem a corroborar as microestruturas apresentadas para estas condições de ciclagem térmica (Figuras 2 e 3e), onde a taxa de aquecimento de $10^{\circ} \mathrm{C} / \mathrm{min}$ em conjunto com temperatura de encharque de $920^{\circ} \mathrm{C}$ e tempo de 3 minutos uma maior homogeneização composicional ao fim do encharque, possibilitando obter uma microestrutura após resfriamento com um menor dispersão do tamanho de grão ferrítico e uma aparente menor fração de perlita.

Por outro lado, comparando-se as amostras submetidas as mesmas condições de taxas de aquecimento $\left(99^{\circ} \mathrm{C} / \mathrm{min}\right)$ e temperaturas de encharques distintas $(680,740$, 800,860 e $920^{\circ} \mathrm{C}$ ), pode-se observar de modo geral um máximo para as propriedades mecânicas extraídas do ensaio de nanoindentação (Figuras de 4 a 7) associada a temperatura de encharque de $740^{\circ} \mathrm{C}$, com um decréscimo posterior das mesmas com o incremento da temperatura de encharque, exceto para a dureza dinâmica elastoplástica, DHV-1 (Figura 5) e módulo da indentação, Eit (Figura 7), que tende a se estabilizarem para os valores de temperatura de encharque de 860 e $920^{\circ} \mathrm{C}$. Fazendo uma associação com as microestruturas resultantes para estas condições de ciclos térmicos (Figura 3), pode-se inferir que os valores superiores das propriedades mecânicas analisadas podem estar associado a um maior enriquecimento de soluto na austenita formada no encharque a $740^{\circ} \mathrm{C}$ possibilitando assim durante 0 resfriamento com taxa de $10^{\circ} \mathrm{C} / \mathrm{min}$ a formação de segunda fase de natureza mais dura que a perlita (como por exemplo, a bainita e até mesmo a martensita), em conjunto com algum resquício de encruamento dos grãos ferríticos (Figura 3b), que não experimentaram uma temperatura suficiente alta e tempo suficiente longo no encharque para completa recristalização (Figura 1). Com o incremento da temperatura de encharque tem-se um progresso da recristalização e um conjunto com um provável empobrecimento de soluto da austenita formada no encharque (temperatura de 800 a 
$920^{\circ} \mathrm{C}$ comparadas com a temperatura de $740^{\circ} \mathrm{C}$ ) que contribuem para obtenção de uma microestrutura final associadas a uma ferrita com maior tamanho de grão e menor fração de fases de segunda fase mais dura. Fator este que contribuiu para obtenção de menores valores de DHV-1 e Eit, propriedades vinculadas a parcela elástica de deformação, as quais reduzem em seus valores em função do incremento da fração de fases mais macia (neste caso a ferrita).

\section{CONCLUSÃO}

Com base nos resultados obtidos e discussão apresentado, o presente estudo da caracterização microestrutural de um aço baixo carbono com microadição de molibdênio e nióbio, pode-se concluir que:

- a taxa de aquecimento adotada para os ciclos térmicos foi suficiente para atrasar a recristalização, impondo que a mesma ocorre-se durante o encharque e se apresentase por completo para temperaturas de encharque superiores ou igual a $800^{\circ} \mathrm{C}$.

- a seleção de temperaturas de encharque mais inferiores no intervalo intercrítico contribuiu para a formação de segunda fase mais dura através do enriquecimento de soluto na austenita formada durante o encharque.

- o estudo do comportamento do material através das propriedades extraídas pelo ensaio de nanoindentação instrumentada, associado a características do comportamento mecânico vinculadas a parcela elástica de deformação (DHV-1 e Eit), permitiu separar os resultados associadas a uma maior contribuição de fases duras em conjunto com uma matriz ferrítica pela faixa de valores atribuídos a estas propriedades.

\section{Agradecimentos}

Os autores agradecem a CSN por ter fornecido o material estudado. A UFF pelos recursos para preparação e caracterização microestrutural via microscopia óptica e mecânica do material. Ao Laboratório de Caracterização de Materiais Multiusuários no Instituto de Ciências Exatas (ICEx) da UFF.

\section{REFERÊNCIAS}

1 Gorni AA. Aços Avançados de alta resistência: microestrutura e propriedades mecânicas - Corte e Conformação de Metais. Dezembro 2008; 3:35: 26-57.

2 Gurgel MAM. Evolução Microestrutural Durante o Processo de Recozimento de um Aço Baixo Carbono com Micro adição de Nióbio e Molibdênio Laminado a frio. [Trabalho de Conclusão de Curso em Engenharia Metalúrgica]. Volta Redonda/RJ, Brasil: Universidade Federal Fluminense; 2013.

3 FURUKAWA, T., MORIKAWA, H., TAKECHI, H., KOYAMA, K. Process factors for highly ductile dual-phase steel sheet, Structure and Properties of Dual-Phase Steels, p. 281-303, R.A. Kot and J.W.Morris, ed. AIME, New York, 1979

4 Ferreira FGN. Influência dos Parâmetros de Recozimento Intercrítico para Obtenção de Aços Bifásicos Laminados a Frio. [Dissertação de Mestrado]. Volta Redonda/RJ, Brasil: Universidade Federal Fluminense; 2014. 